\title{
The climate sensitivity of Antarctic blue-ice areas
}

\author{
Richard Bintanja and Michiel R. van den Broeke \\ Instituul voor Marien en Atmosferisch Onderzoek, Universileil Utrecht, 3508 TA Utrecht, The Vetherlands
}

\begin{abstract}
On time-scales of less than about 100 years, when the ice topography can be considered stationary, the extent of Antarctic blue-ice areas is governed mainly by the surface mass balance. In and near high-elevation blue-ice areas, ablation is due entirely to sublimation. An estimate of the mass-balance profile ranging from a blueice area to the adjacent snow surface is presented. By considering changes in sublimation induced by variations in local climate, the deviation from the massbalance profile is evaluated. It is concluded that even for considerable changes in local climate these deviations remain relatively small and have only little effect on the extent of a blue-ice area. This can be attributed mainly to the steep mass-balance profile.
\end{abstract}

\section{INTRODUGTION}

Although widespread in mountainous regions, Antarctic blue-ice areas occupy only a small part of the total surface area. They are characterized by a negative surface mass balance. Apparently, local conditions at the downwind side of nunataks or mountain ridges are favourable for less accumulation and/or increased ablation. As a result, the surface consists of ice with a relatively low albedo. The marked albedo difference between blue ice and the surrounding snow, together with the presence of easy-totrack rock outcrops, makes blue-ice areas relatively easy to monitor by satellites. It has therefore been suggested that blue-ice area extent can be used as a climate indicator for the Antarctic continent Orheim and Lucchitta, 1990). However, knowledge of the relation between local mass balance and (local) climate change is a prerequisite. A significant advantage is that on timescales of about 100 a or less, changes in ice-sheet topography and ice dynamics can be neglected, in contrast to mountain glaciers, for example. Therefore, variations in blue-ice area extent on these time-scales will be caused only by changes in surface mass balance.

In this paper, we will use data from field experiments to estimate the horizontal mass-balance profile going from a blue-ice area towards the adjacent snow plains. Then changes in the ablation profile resulting from varying local climatic conditions will be estimated using a surface energy-balance model. This can be done because ablation in this particular blue-ice area (and in most of the others) is due mainly to sublimation (as well as some snowdrift erosion), which is one of the surface energy-balance terms. How the changes in local climate relate to changes in global climate should be addressed by global-scale climate models (e.g. general-circulation models), and will not be discussed here.

Since spatial variations in accumulation processes are the most likely cause of the formation of blue-ice areas, the temporal variations in precipitation and snowdrift processes are probably very important for the climate sensitivity of blue-ice areas. However, as this paper focuses on the sublimation and hence the surface energy balance), changes in mass balance due to changes in accumulation, although probably important, will not be considered. For a discussion of the role of drifting snow in blue-ice area formation we refer to Van den Broeke and Bintanja (1995).

\section{DATA AND METHODS}

The field campaign to the Heimefrontfjella, Dronning Maud Land, took place during the austral summer 1992 93, and was hosted by the Swedish Antarctic Research Programme (SWEDARP). Approximately 1.5 months of meteorological data from three of the seven stations on and around the Scharffenbergbotnen blue-ice area see Fig. 1) are used in the present analysis. A detailed description of the instrumentation and data assimilation is given by Bintanja and others (1993). Note that the blueice areas in this region are located at the downwind side of the mountain ridges, a feature similar to other parts of Antarctica.

To relate the meteorological quantities to surface heat fluxes, a surface energy-balance model is used Bintanja and Van den Broeke, 1994, in press. From hourlyvarying input data, such as net solar radiation, long-wave incoming radiation, air temperature, humidity and wind speed, the model calculates the surface energy budget as well as the (sub-) surface temperature distribution. The spatial and temporal variation of the surface heat fluxes around the blue-ice area under consideration is evaluated for the entire 1.5 month summer period. Where surface temperature measurements (site $B$ ) and stake readings (site A) were performed, these directly measured quantities compare rather well with the simulated values obtained using the surface energy-balance model. Therefore, we should expect the model also to be able to 


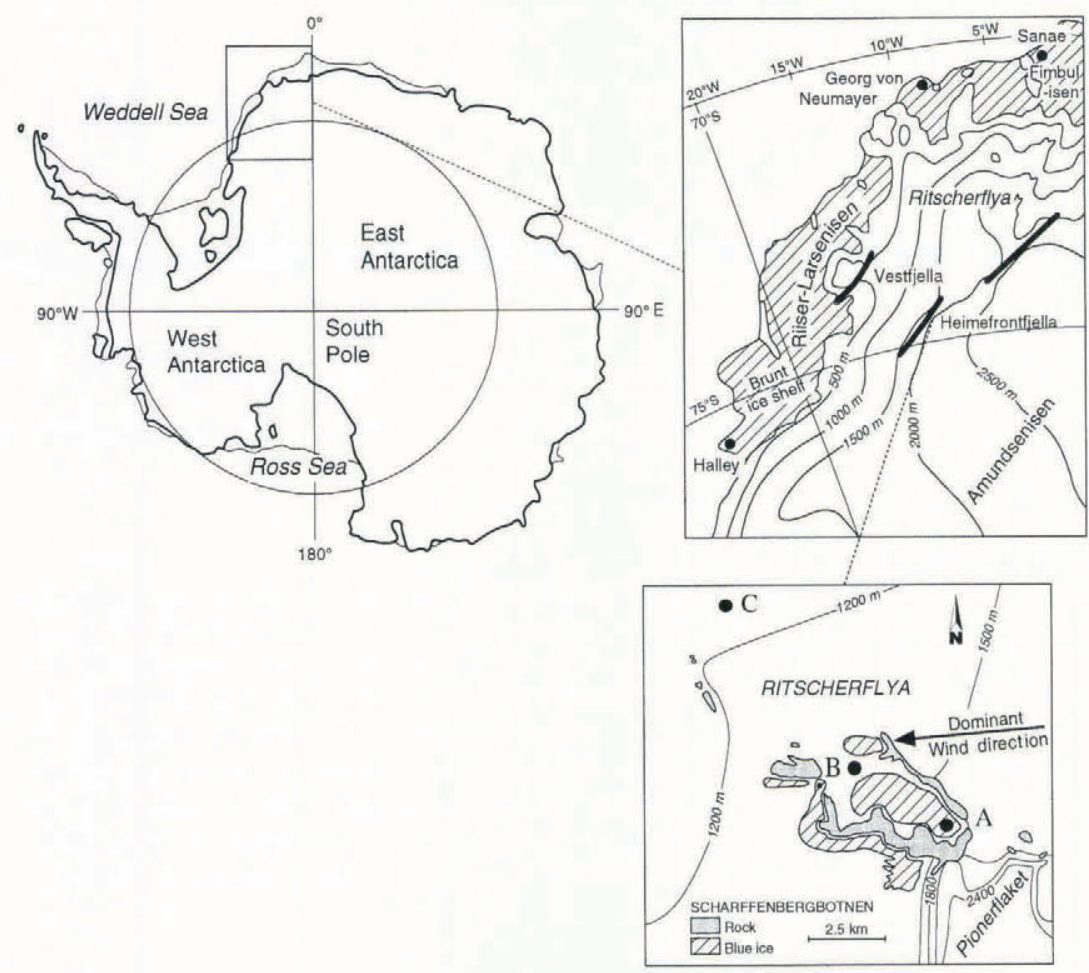

Fig. 1. Location of the Scharffenbergbotnen blue-ice area in Antarctica. In the lower panel the measuring sites $A, B$ and $C$ are shown.

translate perturbations in meteorological conditions to changes in surface heat fluxes with sufficient accuracy. In other words, using the model to recalculate the surface energy budget for changes in local climate will provide an order-of-magnitude estimate of the sensitivity of the surface heat fluxes.

\section{THE MASS-BALANCE PROFILE}

In recent years, the mass-balance distribution in and around the Scharffenbergbotnen valley has been measured extensively by Swedish scientists (e.g. Jonsson, 1992; Näslund, 1992). From these stake measurements the annual mass-balance profile along the measuring sites A, $\mathrm{B}$ and $\mathrm{C}$ (Fig. 1; lower panel) can be estimated, as shown in Figure 2. The mass balance increases from the blue-ice area towards the adjacent snowfields. The blue-ice area is bounded by the equilibrium line, which is located near

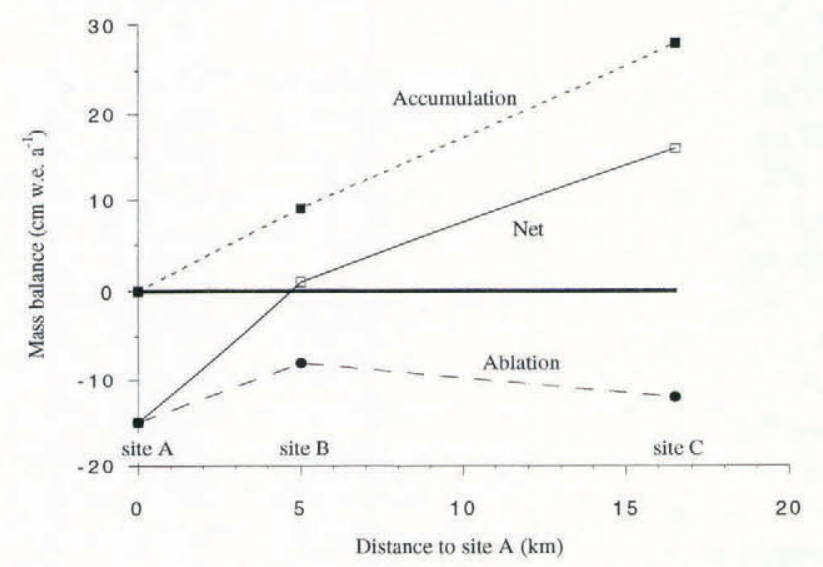

Fig. 2. The annual mean accumulation, ablation and mass-balance profiles along sites $A, B$ and $C$. site B. In order to estimate the contributions of ablation (by sublimation) and accumulation to this mass-balance profile, the annual accumulation near site $\mathrm{A}$ is assumed to be negligible. This is a reasonable assumption since occasional precipitation or deposition of wind-blown snow is usually eroded very quickly by the wind, leading to a nearly continuous exposure of bare ice. Towards the outer bound of the blue-ice area, however, snow can remain on the ice for a longer period of time, as indicated by the presence of snow patches. Since a substantial part of the annual sublimation takes place during summer (Fujii and Kusunoki, 1982), we can relate the sublimation during the 1.5 month measuring period $(4.2 \mathrm{~cm}$ w.e.) to the annual sublimation ( $15 \mathrm{~cm}$ w.e.) at site A. (This is a mean value obtained from stake readings over a 5 year period (1988-93), during which the inter-annual variability amounts to more than $50 \%$ of the average value (personal communication from S. Jonsson, 1994)). From this we can crudely deduce annual sublimation rates from sublimation rates during the experiment for sites $\mathrm{B}$ and $\mathrm{C}$ as well. In other words, we assume the ratio of the measuring-period sublimation to the annual mean sublimation to be spatially invariant. The accumulation rates then follow as the difference between net mass balance and ablation (The net balance near site $\mathrm{C}$ is derived from counting annual layers in firn cores (Jonsson, 1992) and represents a mean over 17 years with inter-annual variations of more than $50 \%$; the net balance at site B is very slightly positive according to stake readings over the years 1988-92 (Näslund, 1992)).

The resulting ablation and accumulation profiles are shown in Figure 2. It appears that the steep mass-balance gradient is caused mainly by the steep accumulation gradient, while the spatial variations in ablation seem to be relatively small. According to Bintanja and Van den Broeke (in press), the differences in sublimation rates 
between blue-ice and snow surfaces are due mainly to the albedo differences. Because of the low albedo of ice 0.56 as compared to snow $(0.80)$, the ice heats more and loses parts of the additional energy by a large, upward-directed latent-heat flux. At site $\mathrm{C}$, where the influence of the upstream rock wall on the surface wind field is small, the wind speed is larger than at sites $\mathrm{A}$ and $\mathrm{B}$ and, consequently, the latent heat flux at site $\mathrm{C}$ is larger than at the wind-shielded site $\mathrm{B}$. This all contributes to the small spatial variation in sublimation rate.

Since precipitation variations over a range of less than $20 \mathrm{~km}$ are likely to be small, the large spatial-accumulation gradient displayed in Figure 2 must be caused by differences in the divergence of wind-blown snow, redistributing the precipitated snow. As stated above, over ice the wind-induced erosion of snow is larger than the deposition. An important aspect herein is the smoothness of the ice, which hinders the snow from keeping firmly attached to the surface. Towards site C the convergence of drifting snow becomes larger, one of the main causes of which may be the deflection of the snowdrift transport around the mountain range (which makes more snow available to be deposited near site $\mathrm{C}$ in comparison with sites $B$ and $A$ ).

\section{SENSITIVITY TESTS}

In a similar manner to that described above, perturbations in the ablation during the measuring period can be related to perturbations in the annual ablation. The surface energy-balance model is used to relate changes in meteorological conditions to changes in surface heat fluxes and hence the sublimation rate). Although a (local) climate change generally consists of a change in a combination of meteorological quantities, here we will perturb each variable one by one. In this way, the importance of a change in each individual meteorological quantity can be evaluated separately. The following perturbations are uniformly (in time) applied at each site $(\mathrm{A}, \mathrm{B}$ and $\mathrm{C})$ :

$$
\begin{aligned}
& \text { air temperature } \pm 3 \mathrm{C} \\
& \text { relative humidity }+5 \% \text { (absolute) } \\
& \text { wind speed } \pm 20 \% \\
& \text { incident short-wave radiation } \pm 20 \mathrm{~W} \mathrm{~m}^{-2} \\
& \text { incoming long-wave radiation } \pm 20 \mathrm{Wm}^{-2} \text {. }
\end{aligned}
$$

Although the uncertainties are large, these seem fairly large perturbations when considering "realistic" climatechange scenarios for the next 100 years. The results can therefore be regarded as upper limits. Note that a change in radiative fluxes of $20 \mathrm{~W} \mathrm{~m}^{-2}$ is far too large to result from changes in atmospheric composition alone. Such a large change can result from changes in cloudiness (cloud amount and/or cloud optical properties), which can be caused by a change in predominant cyclone paths, for instance. Note that for each case the hourly-varying surface energy balance is calculated.

The changes in mass-balance profile for each of the applied perturbations are presented in Figure 3. The general feature is that the change in sublimation rate is
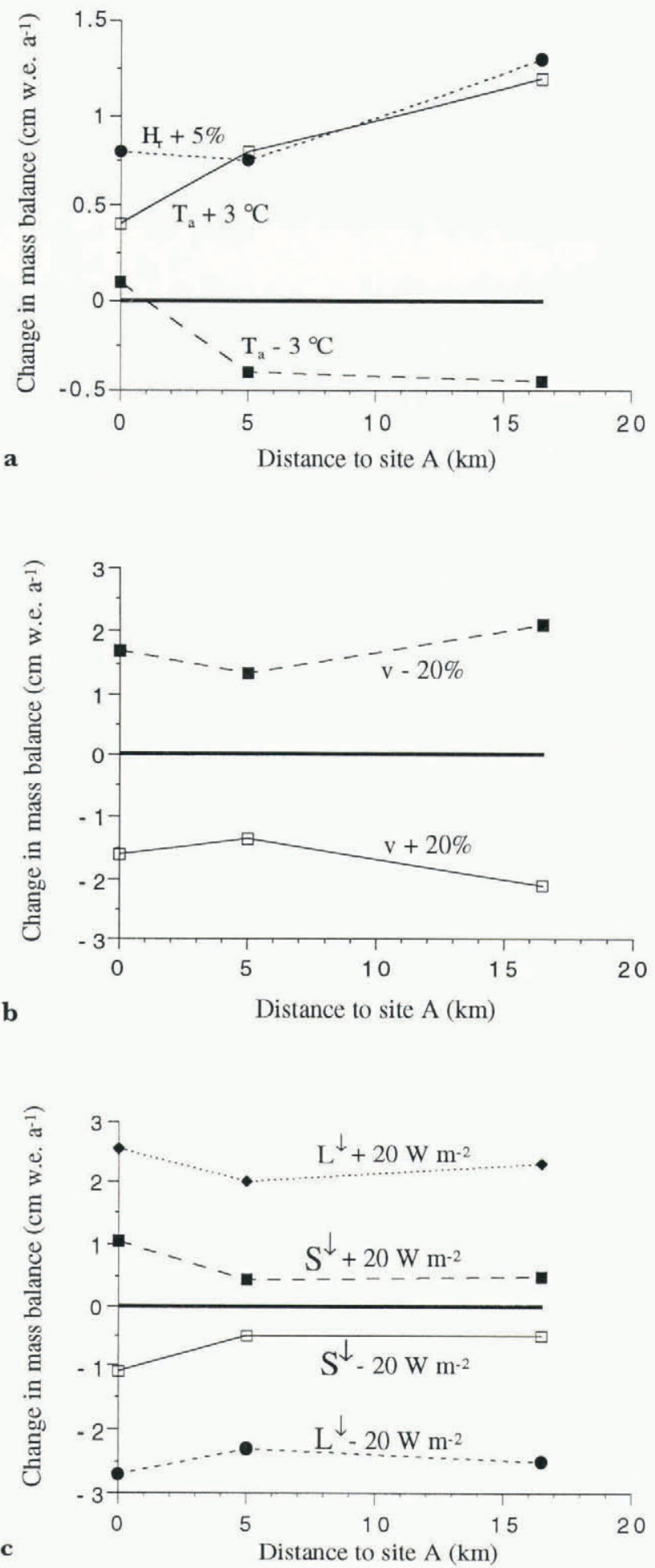

Fig. 3. Change in annual mean mass-balance profile along sites $A, B$ and $C$ for changes in (a) air temperature $\left(T_{\mathrm{a}}\right)$ and relative humidity $\left(H_{\mathrm{r}}\right),(b)$ wind speed $(v)$, and $(c)$ incoming shorl-wave radiation $\left(S^{\downarrow}\right)$ and long-wave radiation $\left(L^{\downarrow}\right)$. Note the differences in verlical scales.

small compared to the actual sublimation rate; the spatial variation of the changes is even smaller. This is not a straightforward result, considering differences between the sites in the dominant mechanisms causing the turbulent motions: shear stress at site $\mathrm{C}$ due to the presence of a rough snow surface and high wind speeds, whereas buoyancy is the dominant turbulent production 
mechanism at site A due to strong heating of the ice (Bintanja and Van den Broeke, in press).

Since surface temperatures remain below the freezing point, an increase in air temperature decreases the sublimation rate due to a decreased vertical moisture gradient. Furthermore, the surface air layer becomes more stable, reducing the turbulent moisture transport. Differences in the change of stability are the main cause of differences in sublimation change, which is smallest at site A. There, the changes in the other surface fluxes (except the short-wave flux) are more pronounced, as can be inferred from Figure 4a. The changes in the net longwave radiation, sensible-heat flux and sub-surface heat flux are all much larger than the change in the latent-heat flux. To a lesser extent, the same holds for sites B and C. The relatively small changes in latent-heat flux can be attributed to the fact that at these low temperatures $(\sim$ $-8 \mathrm{C}$ ), the absolute humidity varies only little with
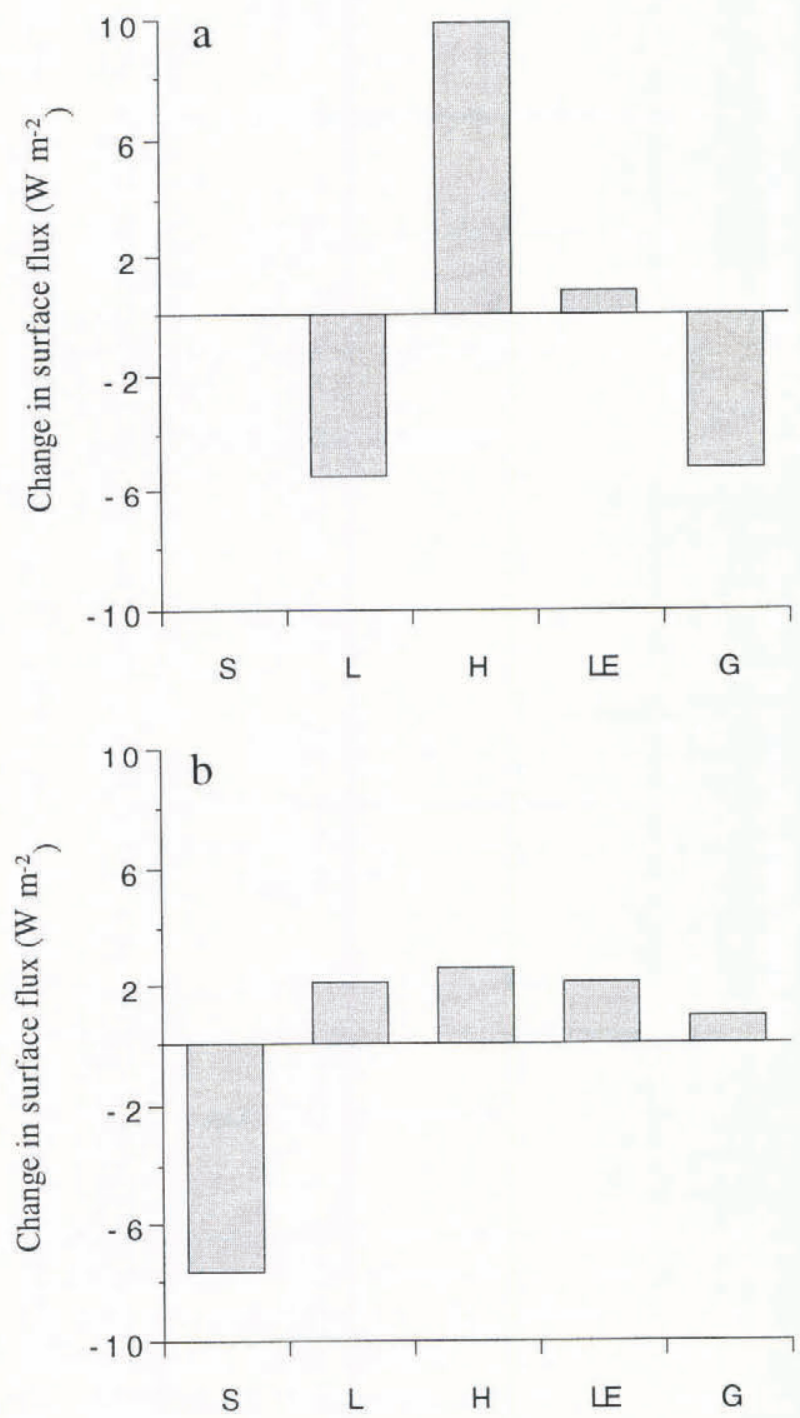

Fig. 4. Mean change of nel shorl-wave radiation $(S)$, net long-wave radiation $(L)$, sensible-heat flux $(H)$, latentheat flux $(L E)$ and sub-surface energy flux $(G)$ for two perturbations at site $A$ : a. air temperature $+3^{\circ} \mathrm{C}$, and $b$. incident short-wave radiation $-20 \mathrm{~W} \mathrm{~m}^{-2}$. A positive value indicates additional flux towards the surface. The values apply to the summer 1992/93 measuring period. temperature. Moreover, the absolute humidity of the air and of the surface change in approximately equal amounts, leaving the vertical moisture gradient and hence the sublimation rate) virtually unchanged.

When the relative humidity of the air increases, the vertical moisture gradient and therefore the sublimation rate decrease. A higher wind speed enhances the vertical turbulent fluxes of sensible and latent heat. Thus, more wind causes more ablation.

When incoming radiative fluxes decrease, the sublimation becomes less. Obviously, less energy is then available for sublimation, although the other surface heat fluxes change as well, as can be inferred from Figure 4b for a decrease of incoming short-wave radiation. It appears that the other fluxes compensate for this loss of energy in approximately equal amounts. The change in sublimation due to an increase in incoming long-wave radiation is larger than for short-wave radiation since a considerable part of the "extra" short-wave radiation is immediately reflected upwards and does not contribute to warming and/or sublimation of the ice/snow surface. Furthermore, snow and especially ice are partly transparent for solar radiation, causing a substantial part of the radiative energy to be used for heating the sub-surface layers. In contrast, all extra incoming long-wave radiation is absorbed at the surface, thereby raising the surface temperature and enhancing sublimation.

The perturbed horizontal mass-balance profiles for changes in incoming long-wave radiation are shown in Figure 5. Obviously, if the situation with increased longwave radiation persisted for a sufficiently long period of time and all other factors remained constant, the blue-ice area would ultimately occupy a larger area. The mass balance at site B would then become negative, the snow at site B would eventually disappear and the blue ice would reach the surface and, by its lower albedo, further enhance sublimation. This constitutes a positive feed-back mechanism, which promotes blue-ice area expansion.

The changes in extent of the blue-ice area, defined as the distance between site $\mathrm{A}$ and the equilibrium line, seem to be relatively small (Table 1) for the perturbations

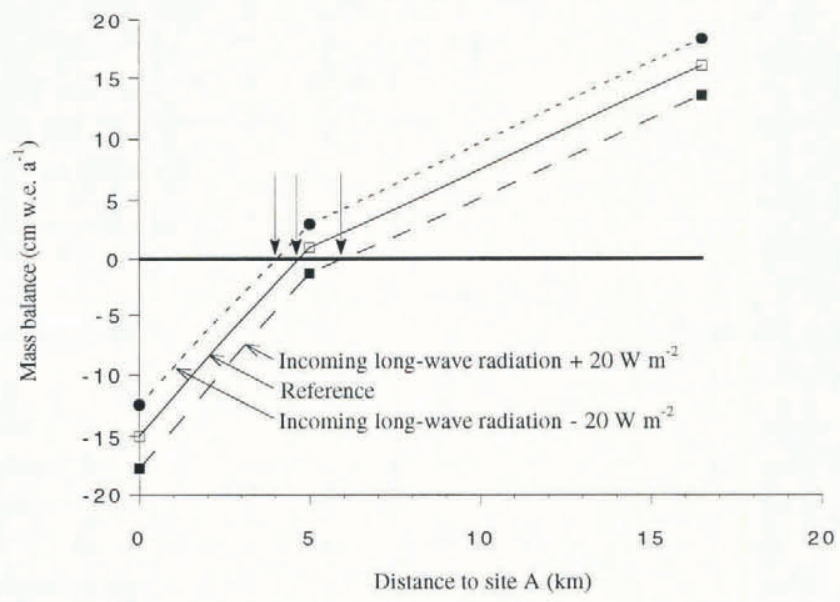

Fig. 5. The annual mean reference and perturbed (incoming long-wave radiation $\pm 20 \mathrm{~W} \mathrm{~m}^{-2}$ ) massbalance profiles. The vertical arrows indicate the equilibrium line for each of the profiles. 
Table 1. Location of the equilibrium line $(E L)$ bounding the blue-ice area, defined as the dislance between site $A$ and the point of zero mass balance, for perturbations in air temperature $\left(T_{\mathrm{a}}\right)$, relative humidity of air $\left(H_{\mathrm{r}}\right)$, wind speed $(v)$, incoming short-wave radiation $\left(S^{\downarrow}\right)$ and incoming long-wave radiation $\left(L^{\downarrow}\right)$. Also shown is the change in equilibrium line with respect to the reference case

Scenario location $\begin{gathered}\text { Change in EL } \\ \text { location }\end{gathered}$
S

$\mathrm{km} \quad \mathrm{km}$

$\begin{array}{llr}\text { Reference } & 4.7 & - \\ T_{\mathrm{a}}+3^{\circ} \mathrm{C} & 4.5 & -0.2 \\ T_{\mathrm{a}}-3^{\circ} \mathrm{C} & 4.8 & +0.1 \\ H_{\mathrm{r}}+5 \% & 4.5 & -0.2 \\ v+20 \% & 5.3 & +0.6 \\ v-20 \% & 4.2 & -0.5 \\ S^{\downarrow}+20 \mathrm{~W} \mathrm{~m}^{-2} & 4.8 & +0.1 \\ S^{\downarrow}-20 \mathrm{~W} \mathrm{~m}^{2} & 4.5 & 0.2 \\ L^{\downarrow}+20 \mathrm{~W} \mathrm{~m}^{2} & 6.0 & +1.3 \\ L^{\downarrow}-20 \mathrm{Wm}^{2} & 4.0 & -0.7\end{array}$

applied here. Although the changes may be relevant in a relative sense (e.g. in the incoming long-wave radiation $+20 \mathrm{~W} \mathrm{~m}^{-2}$ case, the extent of the blue-ice area increases by $28 \%$ ), the absolute changes are small and it seems unlikely that they can easily be detected by satellite. It should also be remembered that some of the changes applied here might well balance each other in a "real" climate change, so realistic changes in blue-ice area extent are probably even smaller.

The main reason for the relative insensitivity of blueice area extent is the steep horizontal mass-balance profile, which allows for only small changes in equilibrium-line location caused by sublimation changes induced by variations in local climate.

\section{DISGUSSIONS AND GONGLUSIONS}

In this paper, the sensitivity of blue-ice area extent resulting from changes in local meteorological conditions is discussed. The changes in meteorological conditions are translated to changes in surface heat fluxes and thus to the sublimation rate) by using a surface energy-balance model. This approach involves various approximations and assumptions, which we expect to affect only the quantitative results. It appears that even for relatively large perturbations in meteorological variables the changes in equilibrium-line location remain fairly small. In the light of the present analysis, this would imply that blue-ice areas would not be very suitable for use as climate indicators for the Antarctic continent, in contrast to what was suggested by Orheim and Lucchitta (1990).
So far, we have only discussed changes in sublimation. One might expect the change in mass-balance gradient resulting from changes in accumulation to be larger than for changes in ablation, since the mass-balance gradient is almost completely determined by the accumulation gradient (Fig. 2). Changes in accumulation involve the complex relationship between the surface wind field and the transport rate of wind-blown snow. Presumably, this problem can best be solved by modelling the surface wind field in terms of the relevant parameters for the persistent Antarctic inversion winds (e.g. surface slope and inversion strength) and parameterizing the transport rate of windblown snow in terms of wind speed (friction velocity) and surface properties. Van den Brocke and Bintanja (1995) use a diagnostic katabatic-wind model to estimate the divergence of drifting snow. They show that in the lee of barriers blocking the drifting snow, snow erosion can become larger than the net accumulation by the other mass-balance terms (e.g. precipitation, sublimation). Furthermore, their analysis indicates that blue-ice area extent may be quite sensitive to changes in inversion strength (and hence surface wind speed) and precipitation rate.

\section{ACKNOWLEDGEMENTS}

The many people and organisations involved in the SWEDARP 1992/93 expedition are acknowledged for their help. Financial support was provided by the Netherlands Antarctic Research Programme GOA and the Dutch National Research Programme on Global Air Pollution and Climate Change (NOP).

\section{REFERENCES}

Bintanja, R. and M. R. van den Broeke, 1994. Local climate, circulation and surface-energy balance of an Antarctic blue-ice area. Ann. Glaciol., 20, 160-168.

Bintanja, R. and M. R. van den Broeke. In press. The surface energy balance of Antarctic snow and blue ice. 7. Appl. Meleorol.

Bintanja, R., M. R. van den Broeke and M. P. Portanger. 1993. A meteorological and glaciological experiment on a blue ice area in the Heimefront Range, Queen .Mand Land, Antarctica. Siea field report. Utrecht. Utrecht University. Institute for Marine and Atmospheric Research.

Brocke, M. R. van den and R. Bintanja. 1995. The interaction of katabatic wind and the formation of blue-ice areas in East Antarctica, 7. Glaciol. (in press).

Fujii, Y. and K. Kusunoki. 1982. The role of sublimation and condensation in the formation of ice sheet surface at Mizuho Station. Antarctica. 7. Geoplys. Res., 87 (6), 42934300.

Jonsson, S. 1992. Local climate and mass balance of a blue-ice area in western Dronning Maud Land, Antarctica. Z. Gletscherkd. Glazialgeol., 26 1). 1990, $11-29$.

Näslund, J. -O. 1992. Blue-ice investigations in the Scharffenbergbotnen basin. In Melander, O. and M. Lömnroth Carlsson, eds. Swedish Antarctic Research Programme 1991/92. A cruise reporl. Stockholm. Swedish Polar Research Secretariat, 48-53.

Orheim, O. and B. Lucchitta. 1990. Investigating climate change by digital analysis of blue ice extent on satellite images of Antarctica. Ann. Glaciol., 14, 211-215. 